\title{
Vibration-based damage identification for reinforced concrete slab- type structures using fiber-optic sensors and random decrement technique
}

\author{
Azita Pourrastegar ${ }^{1 *}$, Hesham Othman $^{1}$, Hesham Marzouk $^{1}$ \\ ${ }^{1}$ Department of Civil Engineering, Ryerson University, Toronto, ON, Canada
}

Received: 03 April 2020 / Accepted: 30 April 2020 / Published online: 08 May 2020

(C) The Author(s) 2020. This article is published with open access and licensed under a Creative Commons Attribution 4.0 International License.

\begin{abstract}
This paper presents and evaluates a damage identification system for reinforced concrete (RC) slab-type structures based on non-destructive vibration testing, Random decrement (RD) signal processing technique, and embedded smart network of fiber-optic sensors. The proposed system aims to overcome the challenges associated with the use of electrical sensors and signal processing of noisy dynamic data. Two experimental modal analysis investigations have been conducted. First modal testing focuses on investigating the capability of fiber-optic sensors and Multi-channel random decrement (MCRD) processing technique to locate damage in RC slabs through changes in the first mode shape response with damage. The second modal testing focuses on the detection of damage intensity using the RD technique through the change in frequency and damping dynamic parameters.

The results show that RD technique can be used effectively to extract the free vibration response of RC slab-type structures; fiber-optic sensors are more sensitive to capture damage severity in comparison to electrical accelerometer sensors, especially, at steel yielding and failure load; MCRD technique can be used effectively to generate mode shapes for RC slabs based on fiber-optic grating FBG sensors measurements. On the other hand, electrical strain gauges were noisy and it was difficult to obtain any measurable data. A damage identification system based on non-destructive vibration testing, MCRD processing technique, and using an embedded smart network of fiber-optic sensors can estimate accurately the damage location through changes in the first mode shape.
\end{abstract}

Keywords: Non-destructive testing; Fiber-optic sensor; Random decrement (RD); Multi-channel random decrement (MCRD); Structural health monitoring (SHM)

\section{Introduction}

Structural health monitoring (SHM) is a technology that allows to detect, measure, locate, and record the changes that affect the performance of a structure. SHM normally involves on-going non-destructive assessment of a structure to evaluate its safety and maintainability based on the change in response to applied loads. Damage identification is one of the essential phases of a SHM practice which aims to detect and locate the damage. Typically, damage is identified by comparing between two different states of the same system, one of which is intact (undamaged) and another one is the damaged state [1].

Vibration based damage identification techniques (VBDIT) can be considered as one of the most popular damage identification method, mainly due to its non-destructive nature and its ability to measured invisible damage from few accessible locations [2]. The basic concept of VBDIT is that structural damage, which alerts the structural stiffness and mass distribution, cause detectable changes in the dynamic response of structures (i.e., natural frequencies, damping values, and mode shapes). VBDIT is based on the concept of monitoring the change in dynamic modal parameters between the intact and damage state. A significant range of research and development, focusing on vibration-based techniques, algorithms, and excitation/sensing methods have been conducted to evaluate their effectiveness in identifying the damage (e.g., [1,3-5]). In summary, sensing instrumentation and measurements processing algorithms are the two main aspects for a robust damage identification system. Additionally, there is no unique existing method that can be used to identify all types of damage in various materials and/or structural member types. For example, some detection methods that work well on metal/beam-type structures might perform poorly when being applied to concrete/slab-type structures. Due to the large scope of this

\footnotetext{
* Corresponding author: Azita Pourrastegar, Email: azita2.pourrastegar@ryerson.ca Tel.: +1-647-621-2375; Fax: +1 (416) 9795122
} 
research area, only the VBDIT for reinforced concrete structures (RC), will be the main focus of this article.

Numerous experimental studies using frequency-based and damping-based methods have been conducted to detect the global damage in RC structures (e.g., [4,6-12]). In summary, it is hard to obtain measurable free vibration decay for RC structural member. Additionally, the changes in the frequency and damping ratio caused by damage are usually very small and may be buried in the fluctuating changes caused by environmental conditions, sensing system sensitivity, noise in the dynamic signal, processing technique. Furthermore, the damping ratio estimated from half-power bandwidth of the spectral densities using Fast Fourier transformations of the random time series were found to have large variance. As a result, it is difficult to obtain reliable free damping measurements as reported in [10-12]. In such cases, the random decrement (RD) technique can be used. RD technique is a method to transform a random time response into a decaying response. $\mathrm{RD}$ is a powerful numerical averaging technique that assumes the forces are zero-mean, stationary Gaussian random process [4,5]. RD technique is categorized as an output based method in which the structural free-vibration response is obtained without knowledge of the excitation force magnitude and/or type [4]. RD estimates dynamic parameters more accurate in comparison with the correlation function method [13]. Noise reduction is another advantage of $\mathrm{RD}$ technique [5]. Owing to its efficiency and simplicity in processing vibration data, RD has been used successfully for several years in the Aerospace SHM industry for metal structures as recommended by Cole in 1973 [14].

Modal shape-based methods are more powerful for damage detection than frequency-based and damping-based methods [1]. Modal shape-based methods are capable of detecting multiple damage (i.e., locate the damage) since mode shapes contain the local information. A worth of mentioning here that the mode shapes of structural members are less sensitive to the environmental effects and do not change significantly with increasing the damage level [7]. Ibrahim, in 1977 extended the RD approach to the MultiChannel Random Decrement (MCRD) technique to determine the mode shape and exact location of the damage in metal structures. MCRD is a method that used to extract the mode shape through applying the RD at multiple points of the structure simultaneously under certain triggering time vector segments [15]. Details about the mathematical derivation, application, and limitation of RD and MCRD techniques are discussed in $[4,5]$. It worth mentioning here that most successfully RD applications have been mainly applied on metals. Concrete is a non-homogeneous material with varying composition of raw materials which has completely different dynamic response than metals. Many researchers have attempted to detect and locate the damage in RC beamtype members based on the absolute change in modal shapes $[4,16]$. Therefore, the application of RD technique is investigated in this paper as a promising technique for processing the dynamic measurements for RC slab-type structures.
Sensing system is the second main component that has a significant influence on the accuracy and reliability of damage identification system, especially, for RC structures. Electrical sensors have for decades been the standard mechanisms for measuring the structural responses (e.g., strains, displacements, accelerations, or environment effects). Strain gauges and accelerometers are the most commonly used electrical sensors for health monitoring. These sensors have proved to be practical in detecting the damage intensity using a few sensors. However, these sensors have inherent limitations such as transmission loss and susceptibility to electromagnetic interference (i.e., noise). Additionally, using such electrical sensing system to extract mode shapes for determining the damage location are impractical and expensive because a large number of sensors and lengthy cables are required to precisely measure the mode shapes. Furthermore, the installation of such devices usually requires the area of a defect to be safe of damage and accessible for testing, that can be difficult and costly for most cases in civil engineering structures. Fiber-optic sensing system is a promising alternative to overcome these challenges. Fiberoptic sensor uses light wave instead of electricity and fiberoptics in place of copper wire, which means fiber-optic sensors are electrically passive, nonconductive, immune to noise, and have a long-term stability/accuracy [17]. A fiberoptic sensor consists of three main layers: the core, the cladding, and the buffer jacketing. The core is a thin strand of silica glass that transmits a light beam. The cladding reflects, stray light back into the core, ensuring the transmission of light through the core with minimal loss. The jacket provides mechanical strength and protection from damage and/or moisture absorption. It is interesting to mention that, several fiber-optic sensors can be connected to one optical channel, which greatly reducing the size/weight, cost, and complexity of the measurement system. Recently, monitoring of a 12-floor steel frame building was performed using 64 embedded fiber bragg grating (FBG) sensors with different applications (strain, temperature, acceleration, pressure, etc.) in the single fiber cable [18]. Due to the obvious advantage of using fiber-optic based sensing system, it has been enrolled in many civil engineering applications. FBG sensors were used to detect cracks in concrete pipes during loading tests [19]. FBG sensors were also installed to measure the behavior of different components of tunnels and dams [20].

This study is part of ongoing research program by the authors aiming to develop a practical and reliable SHM strategy for RC structures based on non-destructive vibration testing and RD signal processing technique using an embedded smart network of fiber-optic sensors in forms of array. The proposed damage identification technique aims to overcome the aforementioned challenges associated with the use of electrical sensors and signal processing of noisy dynamic data. Recently, RD and MCRD approaches were implemented effectively in determining the damage intensity and location in steel and RC one-dimensional members (i.e., beams) using sensitive fiber-optic sensors by the Co-authors [4, 28]. Additionally, RD has been used and verified by the Co-authors to assess the damage intensity in ultra-high performance fiber 
reinforced concrete plates (i.e., two-dimensional elements) using electrical $\pm 50 \mathrm{~g}$ accelerometers [21]. However, there are no available data in literatures for the use of MCRD data processing technique and fiber-optic sensing to detect the damage location in RC slabs.

\section{Experimental investigation}

The main objective of the presented experimental study is to evaluate the effectiveness of fiber-optic sensors and RD technique in detecting and locating the damage in two-way RC slabs. To achieve this goal, two experimental modal analysis investigations have been conducted. First modal testing focuses on investigating the capability of FBG sensors and MCRD processing technique to locate damage in twoway RC slabs. This investigation includes one reference (undamaged) specimen and three other specimens with different levels of artificial predefined damage. The second modal testing focuses on the detection of damage intensity using the same proposed SHM approach. The reference specimen that used to extract the baseline mode shape in the first investigation has been damaged gradually under midpoint monotonic load. Damage progression has been evaluated stepwise based on the change in dynamic parameters and validated by visual inspection. The experimental work and data processing algorithm are fully described in [22] and the main items are presented here.

\subsection{Test specimens}

Four RC plates with identical dimensions and steel reinforcement layout are constructed and tested in the Structural Laboratory of Ryerson University. The RC specimens are $1950 \mathrm{~mm}$ square with a thickness of $100 \mathrm{~mm}$ and clear cover to reinforcement of $15 \mathrm{~mm}$. All slabs are reinforced with equal top and bottom steel reinforcement mats using $10 \mathrm{~mm}$ diameter according to Canadian Standards of Grade 400 with spacing of $210 \mathrm{~mm}$ [23]. The concrete mix used throughout this investigation is a ready-mix highstrength concrete (HSC), with a nominal compressive strength of $65 \mathrm{MPa}$ and $12 \mathrm{~mm}$ maximum aggregate size, supplied by a local concrete plant. All specimens are cast at the same time using a single concrete batch to ensure identical concrete properties. Same supporting conditions are used for all specimens to avoid the influence of boundary conditions on the vibration measurements. As shown in Fig 1, simply supported boundary condition at the four corners is used. This supporting system has been designed to allow a free rotation of the corners. Test Specimens are designed such that, under midpoint static monotonic loading and the considered boundary conditions, a ductile flexural failure governed ultimate capacity with bending-shear capacity ratio of 0.30 . The specimens have been fabricated considering four different levels of damage severity nominated as intact, light, medium and severe damage at a specific location (refer to, Fig. 2). The goal was to simulate an initial crack pattern which is associated with reduction of rigidity and effective dynamic mass of specimen. The induced damage is in the form of artificial small cylindrical holes of $200 \mathrm{~mm}$ diameter. As shown in Fig. 3, the induced artificial damages are created by replacing the concrete section with cylindrical foams during the casting process. Cylindrical foams (sono-tubes), with a diameter of $200 \mathrm{~mm}$ and a depth equal to the slab thickness, are concealed in the slabs and sealed properly for the ease of extracting out from the hardened concrete. The first reference specimen (SO) represents the intact system that has been used to evaluate the baseline dynamic parameters. For the second specimen ( $\mathrm{S} 1$ ), light damage is simulated by creating one cylindrical hole at distance $100 \mathrm{~mm}$ in $\mathrm{x}$ - and 650 $\mathrm{mm}$ in $\mathrm{y}$-directions with respect to one corner. Incrementally, two and three cylindrical holes are created on specimens (S2 and S3) to represent medium and severe damages, respectively.

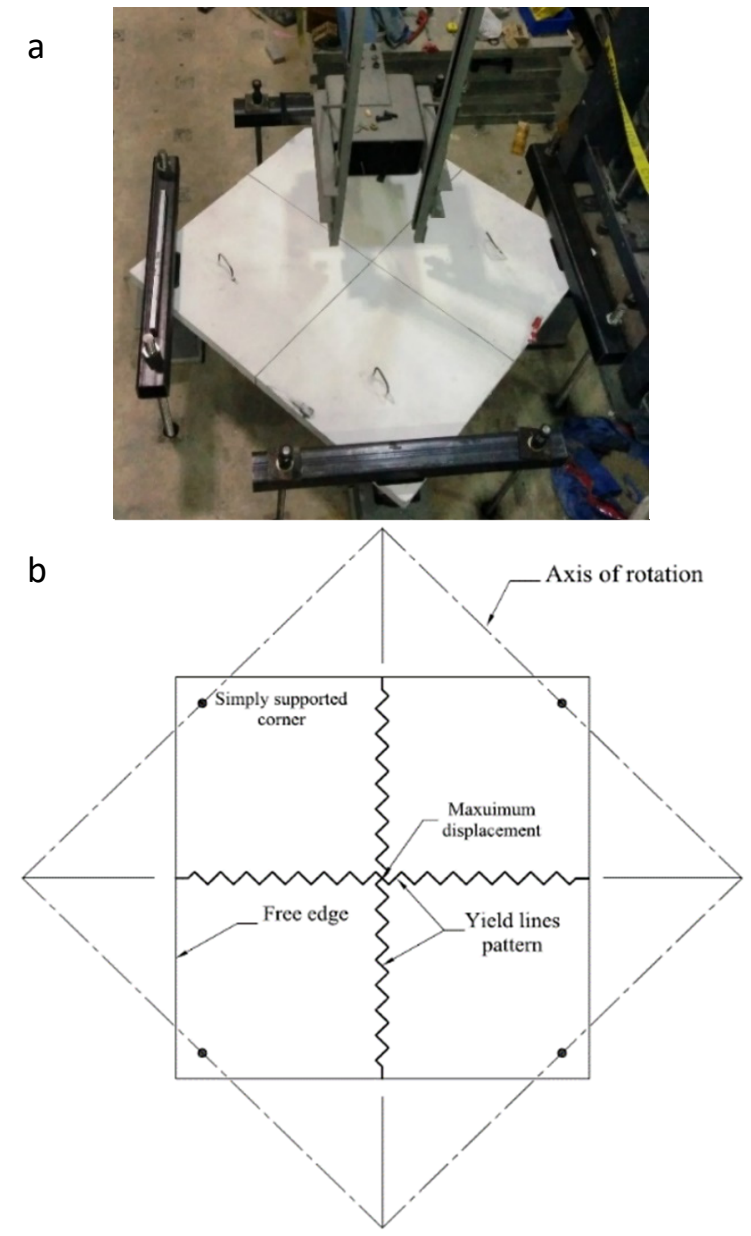

Figure 1. a) Supporting conditions and b) expected fracture pattern

Concurrently with the experimental tests, the basic concrete and steel reinforcement material properties are measured and reported in Table 1. Compression, splitting tensile, mass density tests of concrete are conducted on $100 \times 200 \mathrm{~mm}$ cylinders. Concrete modulus of rupture tests are conducted on $100 \times 100 \times 400 \mathrm{~mm}$ prisms with a clear span of $300 \mathrm{~mm}$. Tensile tests of steel reinforcement are conducted on steel rebars of size $10 \mathrm{M}$ and the density is estimated by weighting one meter length of the rebar. Each data in the table is averaged from three readings. 


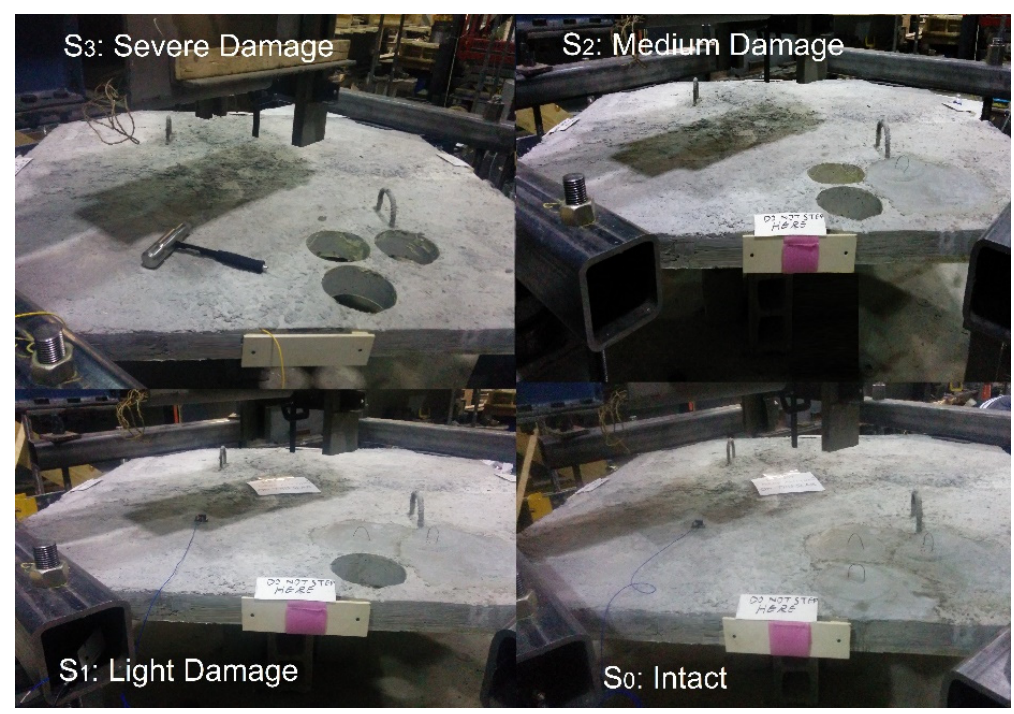

Figure 2. Test specimens with different predefined degrees of damage.

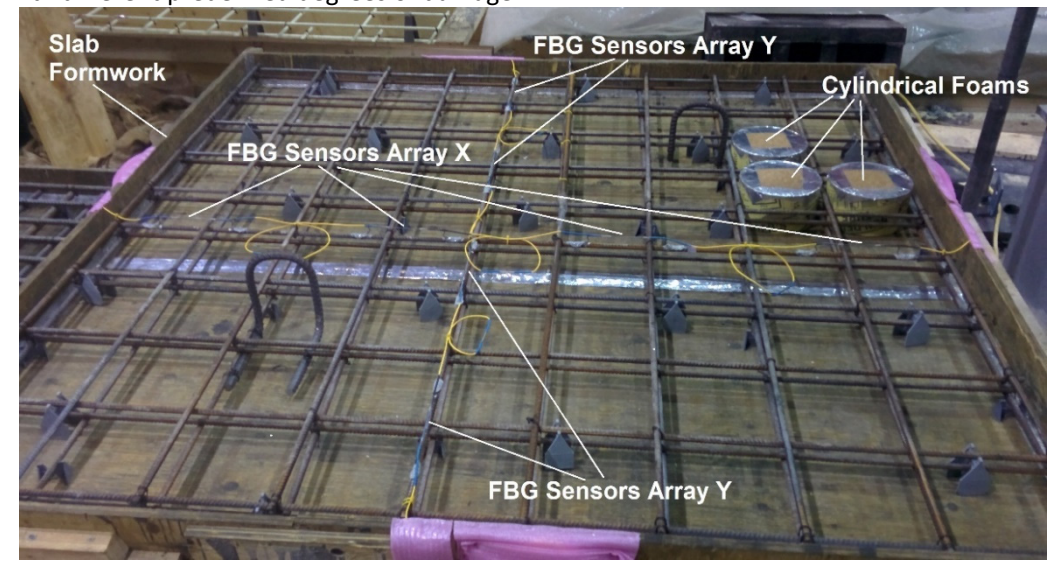

Figure 3. Preparation of artificial damage and FBG sensors before concrete casting.

Table 1 properties of concrete materials and steel reinforcement.

\begin{tabular}{|c|c|c|c|c|c|}
\hline \multirow[t]{2}{*}{$\begin{array}{l}\text { Concrete } \\
\text { HSC }\end{array}$} & $\begin{array}{l}\text { Density } \\
\left(\mathrm{kg} / \mathrm{m}^{3}\right)\end{array}$ & $\begin{array}{l}\text { Compressive } \\
\text { strength } \mathrm{fc}^{\prime},(\mathrm{MPa})\end{array}$ & $\begin{array}{l}\text { Elastic modulus } \\
E_{c},(G P a)\end{array}$ & $\begin{array}{l}\text { Flexural strength } f_{r} \text {, } \\
(\mathrm{MPa})\end{array}$ & $\begin{array}{l}\text { Splitting strength } \mathrm{f}_{\mathrm{tsp}} \\
\text { (MPa) }\end{array}$ \\
\hline & 2510 & 68.10 & 31.20 & 5.90 & 4.50 \\
\hline \multirow[t]{2}{*}{$\begin{array}{l}\text { Steel rebar } \\
10 \mathrm{M} \text { size }\end{array}$} & $\begin{array}{l}\text { Mass } \\
(\mathrm{kg} / \mathrm{m})\end{array}$ & $\begin{array}{l}\text { Diameter } \\
(\mathrm{mm})\end{array}$ & $\begin{array}{l}\text { Elastic modulus } \\
\mathrm{E}_{\mathrm{s}},(\mathrm{GPa})\end{array}$ & Yield stress $\mathrm{f}_{\mathrm{y}},(\mathrm{MPa})$ & $\begin{array}{l}\text { Ultimate strength } \mathrm{f}_{\text {ult, }} \\
(\mathrm{MPa})\end{array}$ \\
\hline & 0.775 & 11.29 & 201.1 & 433.4 & 621.70 \\
\hline
\end{tabular}

\subsection{Modal Testing Instrumentations}

In this investigation, random excitations are applied to RC specimens using a modal impact hammer of $0.5 \mathrm{Kg}$ mass as shown in Fig. 4. The slab structure is a two-dimensional element and its mode shapes could be identified as a onedimensional element in two-orthogonal directions. Therefore, two perpendicular arrays of optical sensors with four measuring points in each cable are installed in each of the four slabs. The used optical sensor is a fiber bragg grating (FBG) which monitors strain over a broad range of frequencies. The gauge length of each FBG is $100 \mathrm{~mm}$. Additionally, a series of electrical strain gauges with a gauge length of $10 \mathrm{~mm}$ are glued to the surface of steel reinforcement at the same locations of FBG sensing points to examine the effectiveness of FBG sensors. The layout of the
FBG sensors, strain gauges, and foam sono-tubes for the artificially damaged specimen with three $200 \mathrm{~mm}$ holes is shown in Fig. 3 . The FBG arrays were manufactured by the Authors in the fiber-optic laboratory of Ryerson University with an effective gauge length of $100 \mathrm{~mm}$ per sensor. The complete details of FBG manufacturing, calibration, prestressing, and vigilant protection during installation can be found in $[17,22]$. The dynamic response of FBG sensors is scanned and recorded at a rate of $952 \mathrm{~Hz}$ using a digital dynamic data acquisition system. The system offers high spectrum resolution combined with broad wavelength range allows measurement of a large number of FBG sensors up to 70. More information regarding FBG acquisition system can be found in [22]. 


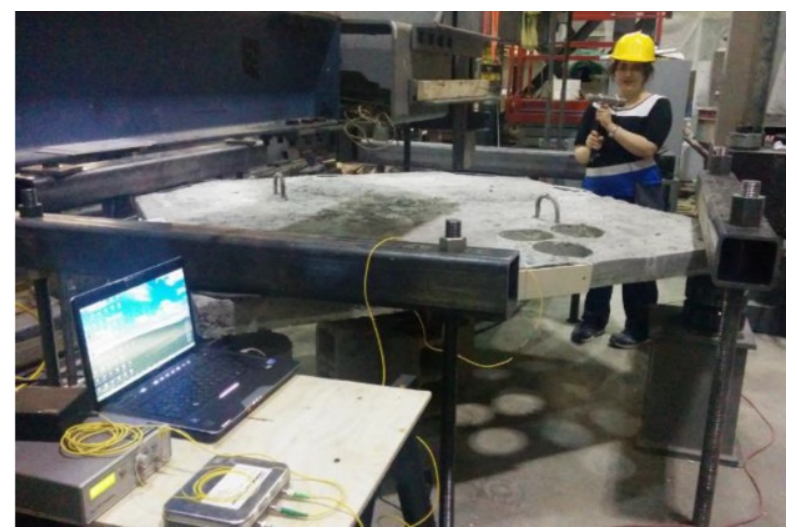

Figure 4. Typical forced vibration test.

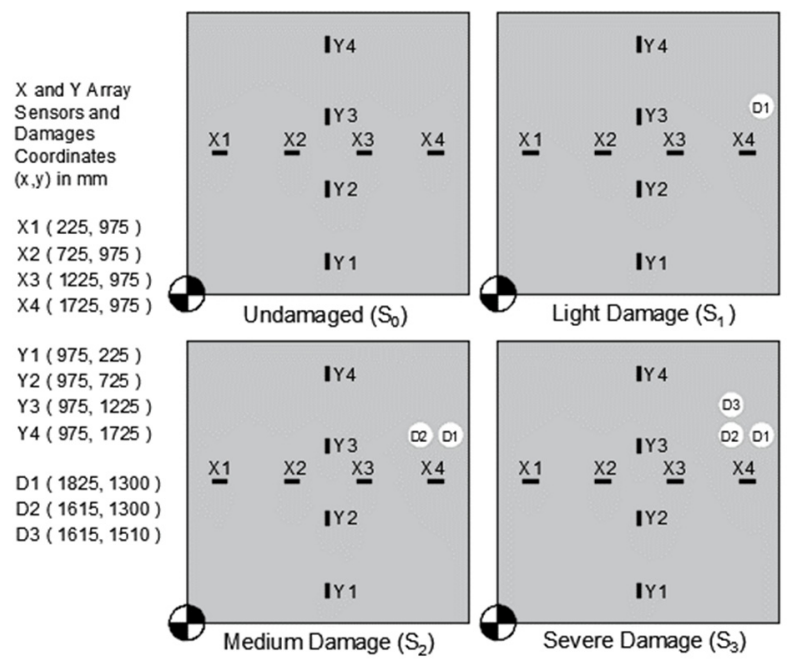

Figure 5. Damage Locations with Respect to FBG Cable Sensors.

\subsection{Damage location testing procedures}

To check the feasibility of the FBG sensing system and MCRD technique in the identification of damage location of two-way RC slabs, the test specimens are supported at the four corners as described, then, the FBG sensors and electrical strain gauges are connected to the monitoring system (Refer to Figs. 3 and 4). It is interesting to mention that eight electrical strain gauges wired separately to the data acquisition, while the two FBG arrays with 8 sensing points are connected only to two channels of the data acquisition system. This is a key advantage of using FBG network, that greatly reduces the cost and complexity of the system.

The used strain type FBG sensor is sensitive to both strain and temperature (i.e., the wavelength of light beam shifts in response to variations in strain and temperature). The FBG sensor wavelengths are measured in the range of 1531.478 to $1549.218 \mathrm{~nm}$. To eliminate the temperature effect, the measurements are acquired three times for both $\mathrm{X}$ - and $\mathrm{Y}$ FBG arrays. Two times with excitation (20 to 30 times randomly by the modal hammer) and one time without excitation for a period of 60 seconds. Then, strain measurements are calculated by a simple subtraction of the FBG reading without excitation from the average FBG readings of excited specimen.

\subsection{Damage intensity testing procedures}

In order to examine the effectiveness of RD technique in extracting the damage intensity of two-way RC slabs, the reference specimen (SO) is subjected to a combination of increasing static load test and dynamic vibration test. The first is performed to gradually introduce the damage in the specimen while the second to determine the dynamic parameters at each damage stage. The specimen has been damaged gradually by applying monotonic midpoint load and the damage state continuously monitored. The load stopped at $5.00 \mathrm{kN}$ increments in order to map the cracks. For easier marking of the crack pattern and monitoring first crack initiation, the specimen is loaded upward from the bottom via a steel block with dimensions of $400 \times 400 \mathrm{~mm}$ and a hydraulic jack supported against the strong floor of the lab. In addition to the two FBG arrays mentioned before, the static testing is well instrumented to develop a reference data. An electrical strain gauge glued to the surface of the top steel reinforcement in the central zone is used to measure the steel strain, linear variable displacement transducer (LVDT) is installed and fixed to a rigid structure on top of the slab to monitor the midpoint displacement, and a load cell is placed between the loading block and the hydraulic jack to measure the applied load. Fig. 6 shows the reference specimen during static testing and the central load vs midpoint displacement curve. As shown, the slab failed in flexural mode as predicted using yield line theory (refer to, Fig. 1). The load-displacement is not smooth due to multi pause operation which was necessary to map the cracks as well as performing vibration testing at different states of damage.

The vibration measurements have been collected mainly at four different states of damage (intact, concrete cracking, steel yield, and ultimate state). Fig. 6 shows the three damage states considered in damage intensity testing. The crack initiation stage is identified by visual inspection and can be shown up clearly in the steep change in the slope of load vs displacement curve. The second damage state considered steel yielding at the midpoint of central reinforcement where corresponding yield strain of 2000 micro-strain has been measured by the electrical strain gauge. The last damage state indicates ultimate where the maximum load could be tolerated by the slab. This stage also depicts the failure of the slab. At each state, the load is released to eliminate its effect as an extra boundary condition at midpoint. Then, the specimen is excited randomly by the hammer 20 to 30 times at the central zone and the vibration response is captured by two $\pm 50 \mathrm{~g}$ accelerometers and FBG sensors. The two accelerometers are installed typical locations positioned above $X 2$ and $Y 2$ FBG sensors (refer to Fig. 5). The measurements of dynamic response of the accelerometers and FBG sensors are sampled at a rate of $2500 \mathrm{~Hz}$. 


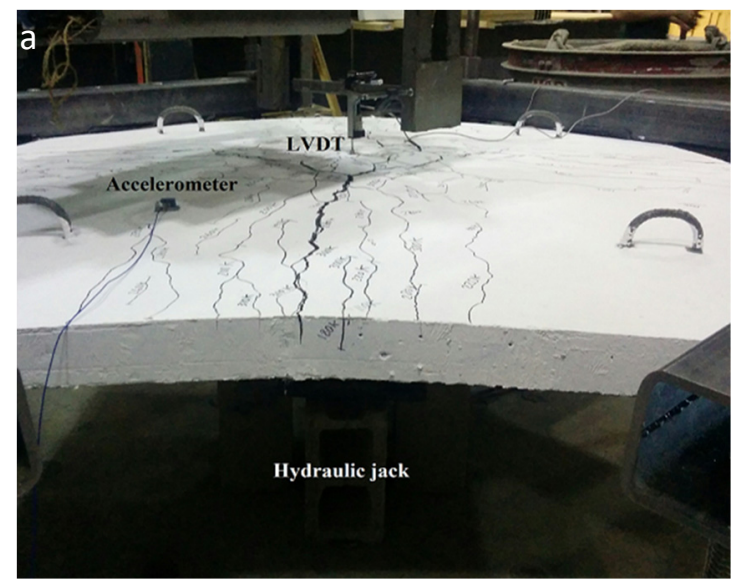

b

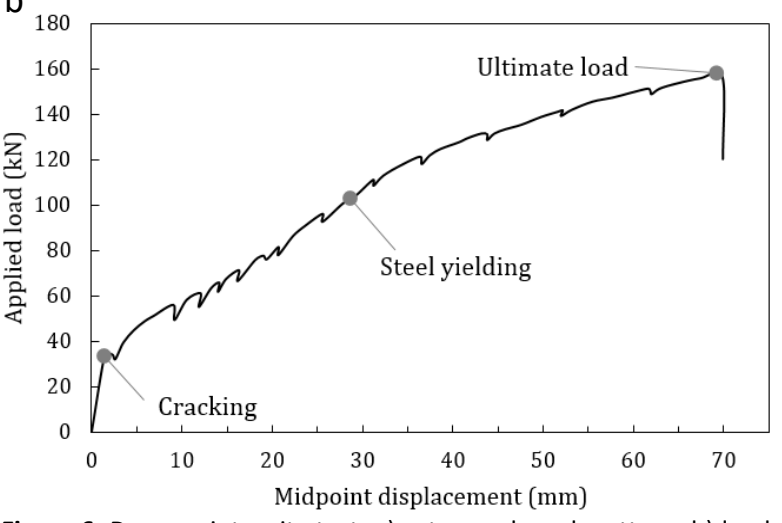

Figure 6. Damage intensity test: a) setup and crack pattern; b) loadmidpoint displacement.

\section{Results and discussions}

\subsection{Damage intensity testing results}

MATLAB software is employed to process the data and a special purpose subroutine is set to carry out RD process. Generally, low frequency modes govern the response, especially, the first mode of vibration which represents the static stiffness of most civil engineering structures [26]. Therefore, a band-pass filter passing a frequency range between 15 and $60 \mathrm{~Hz}$ is used to isolate the first mode shape and to remove white noise from the signals. This frequency range has been selected based on a numerical modal analysis study published in [27]. Fig. 7 presents the raw vertical acceleration response of the reference specimen collected by $\pm 50 \mathrm{~g}$ accelerometers at steel yield damage state. As shown, it is hard to extract useful dynamic parameters from the measured response. RD technique is implemented to check its capability to extract the free decaying response of fundamental mode shape for two-way RC slab. RD signature is unique and equivalent to free decaying response. The RD signature is estimated first based on the average reading of accelerometers at a triggering level of 1.4 times the standard deviation of the response [5]. The integration is conducted using a time increment of 0.4 millisecond and the number of segments used to construct the RD is equal to half of the triggered data number approximately 3000 to 4000 .

Fig. 8 shows an example of acceleration based RD signature extracted of the reference specimen at steel yielding damage state. As shown, the extracted RD signature indicates typical free-vibration response, exponentially decreasing with time due to damping forces. Therefore, RD technique can be considered as an effective tool to extract the dynamic response of two-way RC slabs.

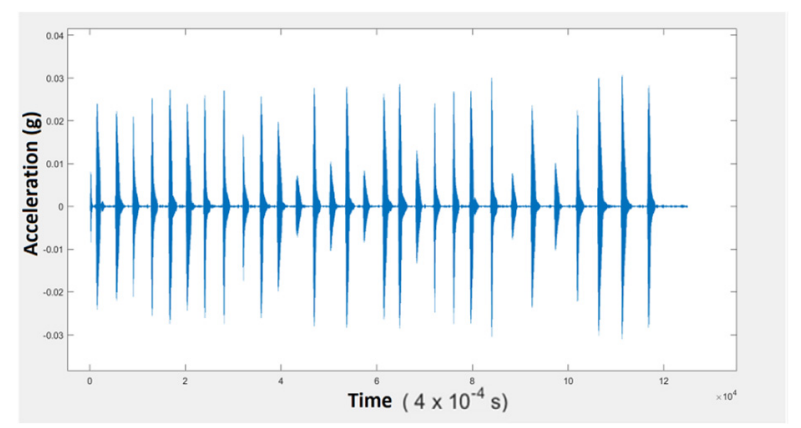

Figure 7. Acceleration time history of the reference specimen at steel yielding damage state.

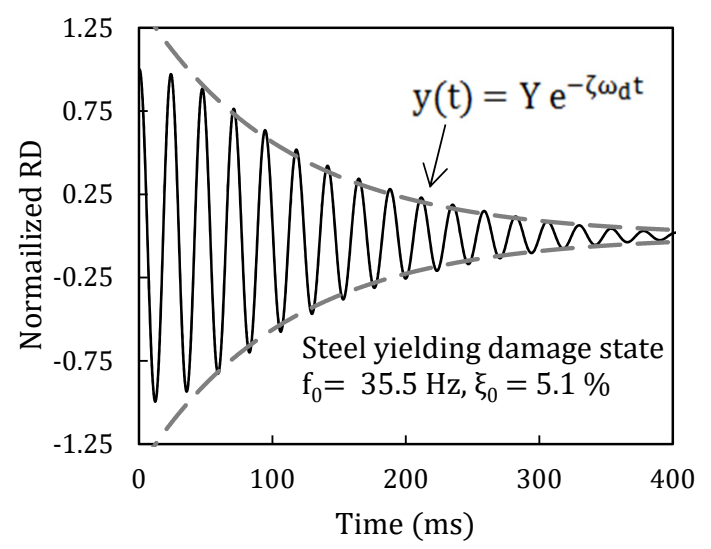

Figure 8. RD signature for reference specimen ( $\mathrm{SO}$ ) at steel yield damage state.

Fig. 9 shows the influence of each damage state on the RD signature of the reference specimen. It is clear that RD technique can be used successfully to extract the damage of $\mathrm{RC}$ two-way slabs which reflects on the dynamic response in the form of significant increase in the time period with increasing damage and change in free decay response.

To examine the sensitivity of FBG sensors in comparison to accelerometers, the extracted RD signatures are followed by modal analysis calculations to estimate the fundamental frequency and associated damping of the RC slabs. The damped period $\left(T_{i}\right)$ is measured directly from the graph using the average of the first six cycles. The natural frequency in Hertz is calculated using: $f_{i}=1 / T_{i}$. The damping ratio $\left(\zeta_{i}\right)$ is estimated using logarithmic decrement approach.

The logarithmic decrement is the rate of decay of free vibration response. Logarithmic decrement $(\delta)$ is calculated using two non-successive cycles of damped vibration as expressed in Eq. 1, and the damping ratio (ろ) is estimated using Eq. 2 [24]:

$$
\begin{aligned}
& n \delta=\ln \frac{Y_{i}}{Y_{i+n}} \\
& \zeta=\frac{\delta}{\sqrt{4 \pi^{2}-\delta^{2}}}
\end{aligned}
$$


Where, $Y_{i}=\mathrm{RD}$ signature amplitude at time $t_{i} ; Y_{i+n}=\mathrm{RD}$ signature amplitude at time $t_{i+n} ; n=$ number of cycles between the two peaks $Y_{i}$ and $Y_{i+n}$.
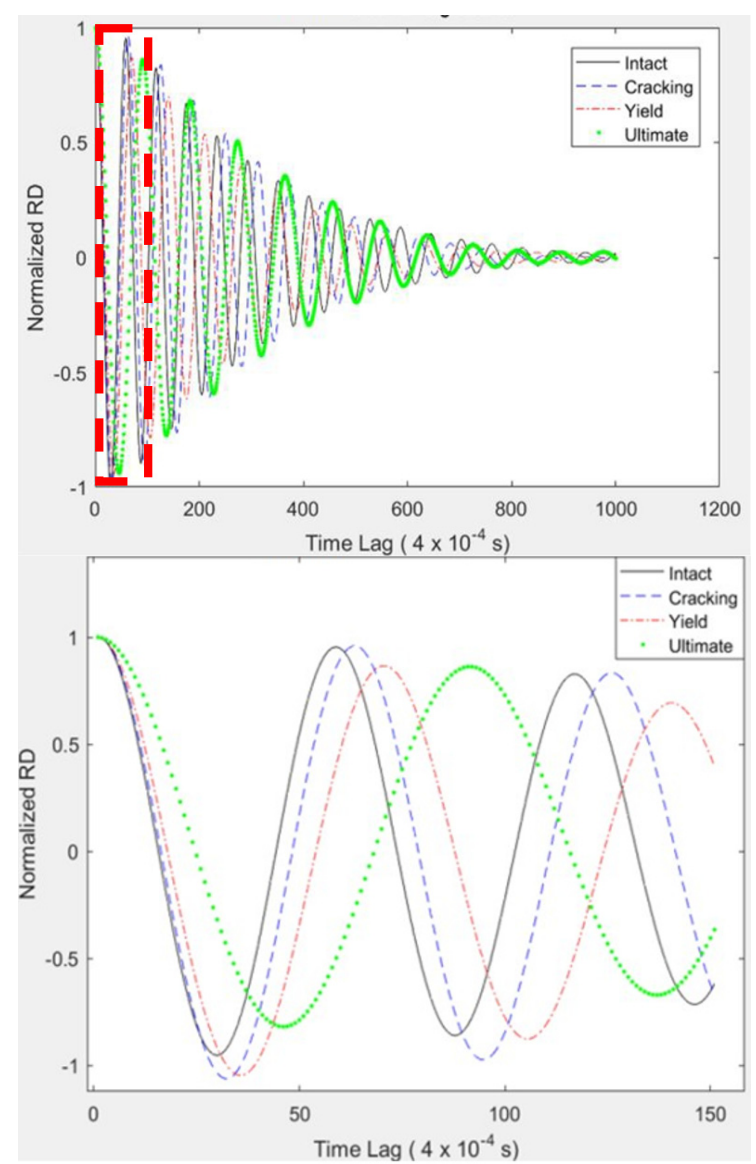

Figure 9. RD signatures for reference specimen (SO) at different damage states.

As a quality assessment, the estimated dynamic parameters using Eqs. 1 and 2 are checked by implementing the extracted natural damped frequency and damping ratio values into Eq. 3 to generate fitting exponential envelope to the RD signature (refer to, Fig. 8) as illustrated in [24].

$$
y(t)=Y e^{-\zeta \omega_{d} t}
$$

Where, $Y$ is the maximum free vibration amplitude that decays exponentially with time $t ; \omega_{d}$ is the circular damped natural frequency estimated in rad/s using $\omega_{d}=2 \pi f_{i}$
The natural frequency $\left(f_{i}\right)$ and associated damping ratio $\left(\xi_{i}\right)$ extracted from both accelerometers and FBG are summarized in Table 2 side by side with the applied static load, midpoint displacement, and steel strain at each damage level. It is obvious from Table 2 that both frequency and damping ratio histories are affected by the damage level and both parameters follow clear trends with increasing damage. Frequency histories decayed with damage progression. On the other hand, damping ratio increased with growing degradation. These observations are consistent with theoretical expectation of damage effect on frequency and damping histories. Additionally, both independent measuring sensors (i.e., accelerometers and FBG) give similar information, especially, for intact state. However, the dynamic parameters estimated based on strain measurements of FBG sensor show the damage more clearly in comparison to accelerometer measurements with increasing damage state. This observation is consistent with the conclusion cited in [25] regarding damage identification methods that directly use acceleration measurements are not sensitive enough to capture damage severity in comparison to strain based methods.

\subsection{Damage location testing results}

In this section, the applicability of MCRD technique and FBG sensors to extract the damage location based on the changes in mode shapes is presented and evaluated. Additionally, incremental, artificial, damages were introduced in test specimens to investigate the sensitivity of FBG sensors (100 measuring length) in comparison to electrical strain gauges (a gauge length of $10 \mathrm{~mm}$ ) in extracting the dynamic parameters. However, the responses of electrical strain gauges were noisy, and it was difficult to obtain any measurable data. On the other hand, the FBG sensors have the advantage of electromagnetic immunity and are successfully used to generate the free vibration response. Therefore, only the FBG data have been processed. The RD signatures are estimated using the same procedures mentioned before. Once the responses are captured, normalized RD is estimated using triggering level equals to 1.4 times the standard deviation of the response. The damage location is investigated through changes in the first mode shape. A special purpose subroutine is set using Matlab to carry out MCRD process (i.e., extract the mode shape).

Table 2. Dynamic properties of reference specimen (SO) at different damage levels.

\begin{tabular}{|c|c|c|c|c|c|c|c|}
\hline \multirow{2}{*}{$\begin{array}{l}\text { Damage } \\
\text { level }\end{array}$} & \multirow[t]{2}{*}{ Load (kN) } & \multirow[t]{2}{*}{ Displacement (mm) } & \multirow[t]{2}{*}{ Steel strain $(\mu \varepsilon)$} & \multicolumn{2}{|c|}{ Frequency $\mathrm{f}_{\mathrm{i}}(\mathrm{Hz})$} & \multicolumn{2}{|c|}{ Damping, $\xi_{\mathrm{i}}(\%)$} \\
\hline & & & & Acc & FBG & Acc & FBG \\
\hline Intact & 0.0 & 0.00 & 0.0 & 42.9 & 43.0 & 4.1 & 4.2 \\
\hline Cracking & 35.1 & 2.85 & 172.0 & 40.0 & 37.3 & 4.4 & 4.8 \\
\hline $\begin{array}{l}\text { Steel } \\
\text { yielding }\end{array}$ & 100.0 & 27.48 & $2,000.0$ & 35.5 & 31.9 & 5.1 & 5.7 \\
\hline Ultimate & 156.1 & 69.95 & $3,680.0$ & 28.9 & 26.1 & 5.8 & 6.4 \\
\hline
\end{tabular}


The first mode shapes in both $x$ and $y$-directions of the test specimens at the four different levels of damage severity (intact, light, medium and severe damage) are shown in Fig. 10. A typical first mode shape of two dimensional plate supported at the four corners is generated using MCRD technique and FBG sensors. Unlike electrical strain gauge data that were noisy and hard to process, the FBG sensors are sensitive to localize damage and estimate the severity of damage. The discrepancy or the amplitude changes in $x$ direction reveal that the damage could be close to measuring point X4 (refer to Fig. 5) and increases with the severity of damage. Same observation can be obtained from the change of the amplitude in y-direction. The discrepancy reveals that the damage exists between measuring points $Y 3$ and $Y 4$. The effectiveness of MCRD combined with FBG sensors in extracting damage location shows up clearly in the change in modal amplitude at measuring point Y4. For damaged specimens S1 and S2, where the damage was mainly existed within measuring point $Y 3$ region, the change in modal amplitude of $Y 4$ is insignificant. However, when the damage extended towards Y4 (specimen S3) at severe damage state specimen, the discrepancy in $\mathrm{Y} 4$ amplitude became more pronounced. Based on the discrepancy in modal amplitude, the damage located at the intersection of $X 4$ and the region between Y3and $\mathrm{Y} 4$ grids.

a

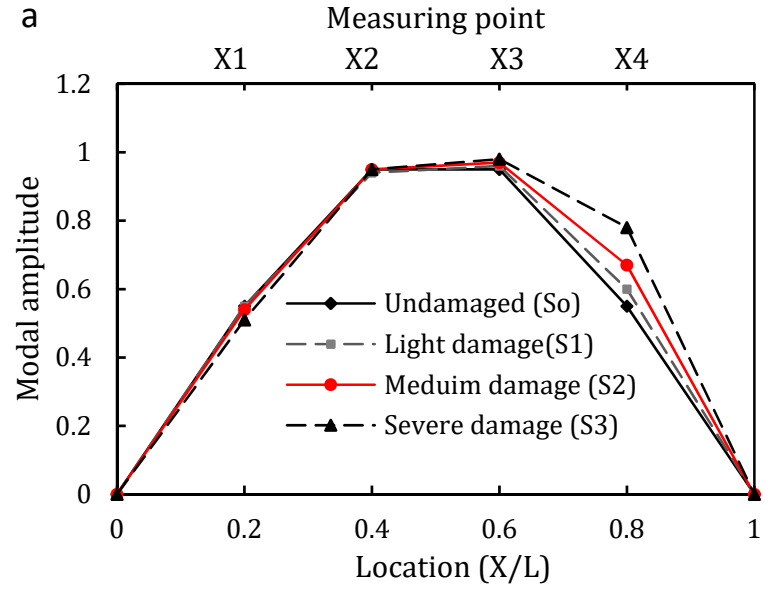

b

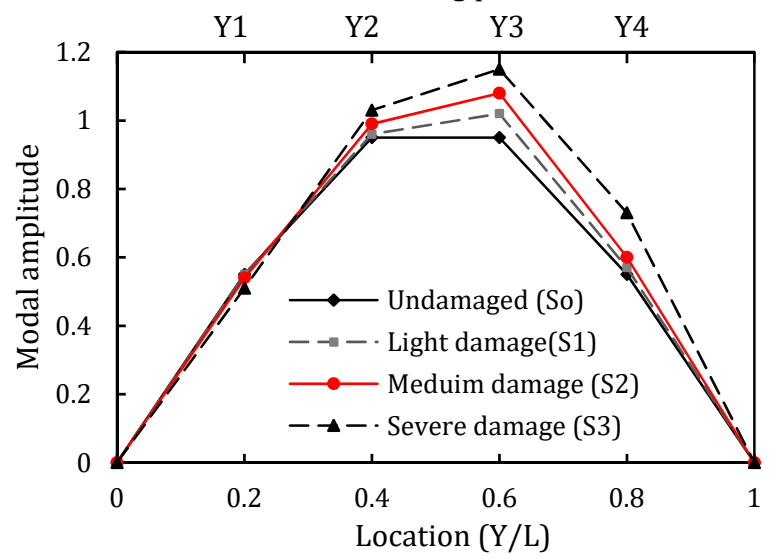

Figure 10. First mode shapes at different damage levels extracted by MCRD: a) Array X, b) Array Y.
According to results, 8 FBG sensors in two orthogonal arrays are quite sufficient for localizing ongoing damage on two-way slab using MCRD mode shape analysis. Another advantage of this damage monitoring system is that after repairing it can show how satisfactory would be the repair procedure.

\section{Conclusions}

This experimental investigation aims to develop a practical and reliable SHM strategy for RC two-way slabs in order to overcome the challenges associated with the use of electrical sensors and signal processing algorithm of noisy dynamic data. The proposed damage identification system based on non-destructive vibration testing, RD signal processing technique, and using an embedded smart network of fiberoptic sensors in forms of array. The main objective of the presented experimental study is to evaluate the effectiveness of fiber-optic sensors and RD technique in detecting and locating the damage in RC slab-type structures. To achieve this goal, two experimental modal analysis investigations have been conducted. First modal testing focuses on investigating the capability of FBG sensors and MCRD processing technique to locate damage in two-way RC slabs through changes in the first mode shape with damage. The second modal testing focuses on the detection of damage intensity using the RD technique through the change in frequency and damping dynamic parameters.

1. RD technique can be used effectively to extract the free vibration response of RC slab-type structures.

2. Fiber-optic sensors are more sensitive to capture damage severity in comparison to electrical accelerometer sensors. The change in dynamic parameters estimated based on strain measurements of FBG show the damage more clearly in comparison to accelerometer measurements with increasing damage state, especially, at steel yielding and failure load.

3. MCRD technique can be used effectively to generate mode shapes for RC two- way slabs based on FBG sensors measurements. On the other hand, electrical strain gauges were noisy and it was difficult to obtain any measurable data.

4. A damage identification system based on non-destructive vibration testing, MCRD processing technique, and using an embedded smart network of fiber-optic sensors can estimate accurately the damage location through changes in the first mode shape.

\section{Acknowledgments}

This research program was financially supported by the Natural Sciences and Engineering Research Council of Canada (NSERC) grant number 1-51-32669. The authors would like to acknowledge the assistance given by the technical staff of the structural laboratory of Ryerson University, specially Mr. Nidal Jaalouk.

\section{References}

[1] H.Sohn, C.R. Farrar, F.M. Hemez, J.J. Czarnecki. A Review of Structural Health Monitoring Literature: 1996-2001. Los Alamos, New Mexico (2004). 
[2] W. Fan, P. Qiao. Vibration-based Damage Identification Methods: A Review and Comparative Study. Struct Health Monit (2011) 10: 83111. https://doi.org/10.1177/1475921710365419

[3] E.P. Carden, P. Fanning. Vibration based condition monitoring: A review. Struct Health Monit (2004) 3:355-377. https://doi.org/10.1177/1475921704047500

[4] R. Morsy, H. Marzouk, X. Gu, A. Elshafey. Use of the random decrement technique for nondestructive detection of damage to beams. Mater Struct (2016) 49: 4719-4727. https://doi.org/10.1617/s11527-016-0819-3

[5] A. Elshafey, M.R. Haddara, H. Marzouk. Identification of the excitation and reaction forces on offshore platforms using the random decrement technique. Ocean Eng (2009) 36: 521-528. https://doi.org/10.1016/j.oceaneng.2009.02.005

[6] M. Haroun, S. Mourad, N. Flynn. Modal Characteristics of RC pier walls before and after cyclic testing. Proceedings of the 11th International Modal Analysis Conference, Florida, USA, Vol. II: 12991302, 1993.

[7] J. Slastan, S. Pietrzko. Changes of RC-beam modal parameters due to cracks. Proceedings of the 11th International Modal Analysis Conference, Florida, USA, Vol I, 70-76, 1993.

[8] R. Perera, C. Huerta, J.N. Orquín. Identification of damage in RC beams using indexes based on local modal stiffness. Constr Build Mater (2008) 22: 1656-1667. https://doi.org/10.1016/i.conbuildmat.2007.06.012

[9] H.A. Razak, F.C. Choi. The effect of corrosion on the natural frequency and modal damping of reinforced concrete beams. Eng Struct (2001) 23: 1126-1133. https://doi.org/10.1016/S0141-0296(01)00005-0

[10] O. Salawu, C. Williams. Bridge assessment using forced-vibration testing. J Struct Eng (1995) 121: 161-173. https://doi.org/10.1061/(ASCE)0733-9445(1995)121:2(161)

[11] A.C. Aparicio, J.R. Casas. Structural Damage Identification from Dynamic-Test Data. J Struct Eng (1994) 120: 2437-2450. https://doi.org/10.1061/(ASCE)0733-9445(1994)120:8(2437)

[12] C.R. Farrardag, D.A. Jaureguiddag. Comparative study of damage identification algorithms applied to a bridge: I. Experiment. Smart Mater Struct (1998) 7: 704-719. https://doi.org/10.1088/0964$1726 / 7 / 5 / 013$

[13] S.H. Sim, B.F. Spencer, H. Jo, J.F. Carbonell-Márquez. Decentralized random decrement technique for data aggregation and system identification in wireless smart sensor networks. Solid Mechanics and its Applications (2011) 29: 305-314. https://doi.org/10.1007/978-94-007-0732-0 30

[14] H. Cole. On-line failure detection and damping measurement of aerospace structures by random decrement signatures. NASA CR2205, 1973.

[15] S.R. Ibrahim. Random Decrement Technique for Modal Identification of Structures. J Spacecraft Rockets (1977) 14: 696-700. https://doi.org/10.2514/3.57251

[16] A.A. Elshafey, H. Marzouk, M.R. Haddara. Experimental damage identification using modified mode shape difference. J Mar Sci App (2011) 10:150-155. https://doi.org/10.1007/s11804-011-1054-5

[17] Z. Yazdizadeh. Use of Fiber Brag Gating Sensors in Civil Engineering Applications; MSc. Thesis; Ryerson University, 2014.

[18] H. Iwaki, H. Yamakawa, A. Mita. Health monitoring system using FBGbased sensors for a 12-story building with column dampers. Smart Structures and Materials and Nondestructive Evaluation for Health Monitoring and Diagnostics (2001) 471-477. https://doi.org/10.1117/12.434147

[19] N. Yasue, H. Naruse, J. Masuda, H. Kino. Concrete Pipe Strain Measurement Using Optical Fiber. IEICE Transactions on Electron C (2000) 468-74.

[20] B. Glisic, M. Badoux. Monitoring a subterranean structure with the SOFO system. Tunnel Management International Magazine (2000) 2: 22-7.

[21] H. Othman, H. Marzouk. Dynamic identification of damage control characteristics of ultra-high performance fiber reinforced concrete. Constr Build Mater (2017) 157:899-908. https://doi.org/10.1016/i.conbuildmat.2017.09.169

[22] A. Pourrastegar. Two Way Slabs Structural Health Monitoring Based on Random Decrement Technique. Ryerson University, 2017.

[23] CSA A23.3 Design of Concrete Structures (Canadian Standards Association). Mississauga, Canada, 2004.

[24] A. Chopra. Dynamics of Structures: theory and applications to earthquake engineering. 4th ed. New Jersey, USA, Pearson Education, Inc. 2012.
[25] Z.A. Jassim, N.N. Ali, F. Mustapha, N.A. Abdul Jalil. A review on the vibration analysis for a damage occurrence of a cantilever beam. Enf Fail Anal (2013) 31:442-61. https://doi.org/10.1016/j.engfailanal.2013.02.016

[26] P. Reynolds. The effects of raised access flooring on the vibrational performance of long-span concrete floors. Dissertation, University of Sheffield, 2000.

[27] H. Othman. Performance of Ultra-High Performance Fibre Reinforced Concrete Plates under Impact Loads. Dissertation, Ryerson University, 2016.

[28] A. Elshafey, H. Marzouk, X. Gu, M. Haddara, R. Morsy. Use of fiber Bragg grating array and random decrement for damage detection in steel beam. Eng Struct (2016) 106: 348-354. https://doi.org/10.1016/j.engstruct.2015.10.046 